\title{
The Effect of Sulcular Injection of Fucose in The Treatment of Gingivitis. An Experimental Study On Rabbits
}

\author{
Chenar A. Mohammad
}

B.D.S, M.Sc., Ph.D., (perio.), College of Dentistry, Hawler Medical University

ABSTRACT

Background: $\alpha$-L- Fucose is one of the eight essential monosaccharides, which is a common component of

many nitrogen and oxgyen linked glycans of glycoproteins and glycolipids produced by mammalian cells. The objective of this study is to evaluate the histopathological effect of local injection of $50 \mu \mathrm{l}$ of $150 \mathrm{mM}$ fucose into rabbits with gingivitis.

Materials and Methods: The existing study was carried out on 60 male rabbits. From the total number 5 rabbits with healthy gingiva had been taken and scarified, while an experimental gingivitis had been induced to the rest 55 rabbits and were divided randomly into 3 main groups; first group consisted of 5 rabbits with gingival inflammation only and were not received any local injection and considered as a base line gingivitis non injected group ; second group consisted of 25 rabbits with gingival inflammation and were injected with $50 \mu \mathrm{l}$ of normal saline into the bottom of gingival sulcus of mid-labial area of lower right central incisor and considered as gingivitis saline injected group ; third group consisted of 25 rabbits with gingival inflammation and were injected in the same area with $50 \mu \mathrm{l}$ of $150 \mathrm{mM}$ fucose solution and considered as gingivitis fucose injected group. Then periodontal tissue biopsy was collected from both saline and fucose injected subgroups at different time intervals of $1,3,7,14$, and 21 days after injection, from gingivitis non injected group, and from rabbits without gingival inflammation .

Results : The results showed that fucose injection resulted in rapid reepithelization, reduction of inflammatory reaction, and fibrous tissue regeneration in short duration of time after injection.

Conclusion: $\alpha$-L- Fucose can be used as anti-inflammatory agent in the treatment of gingivitis (gingivitis induced by plaque).

KEY WORDS

$\alpha$-L- Fucose, experimental gingivitis, periodontal biopsy, sulcular injection.

CITE THIS ARTCLE

Mohammad C. The Effect of Sulcular Injection of Fucose in The Treatment of Gingivitis. An Experimental Study On Rabbits. Iraqi Dent. J. 2016; 38(1):48-57. http://www.iraqidentaljournal.com

$$
\begin{aligned}
& \text { تأ ثير حقن جيب اللثة بأ لفيوكوز في علاج ألتهاب اللثة } \\
& \text { دراسه تجريبية على ألارانب }
\end{aligned}
$$

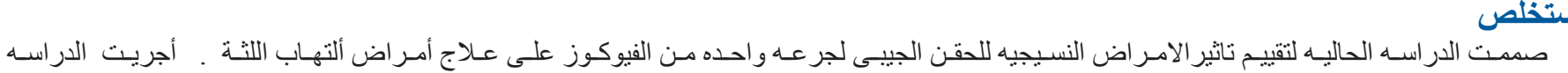

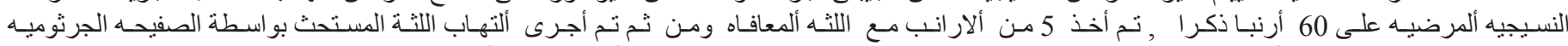

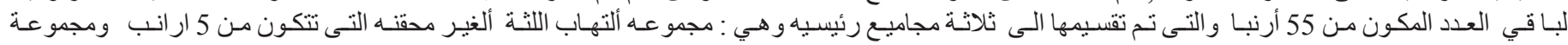

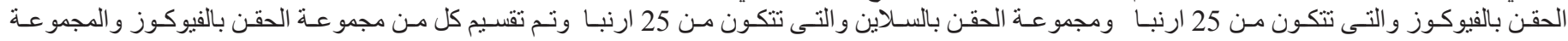

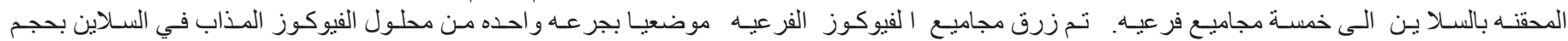

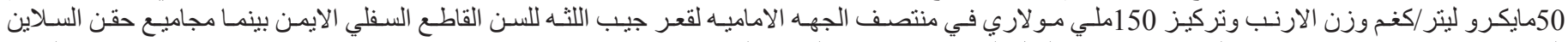

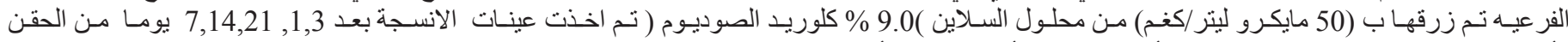

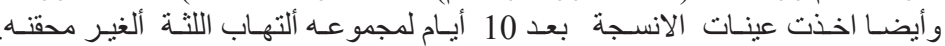

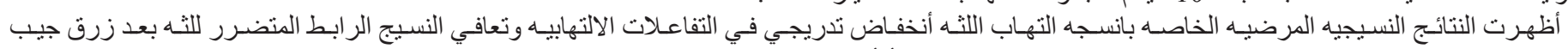

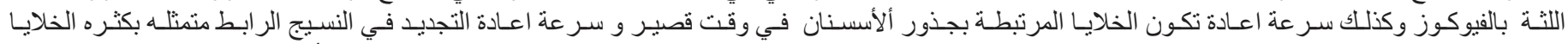

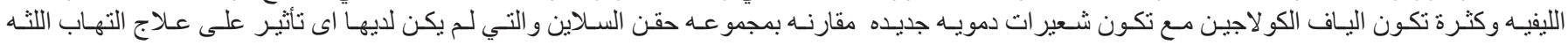

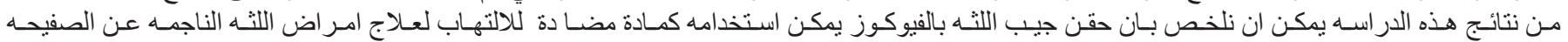

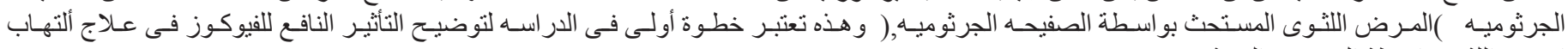

\section{INTRODUCTION}

Periodontal disease is an infectious disease that affects the periodontium, it refers to two associated dental health problems, gingivitis and periodontitis ${ }^{(1)}$. Gingivitis is a reversibly inflammatory reaction confined to the gingiva as a reaction to dental plaque biofilm, and it is characterized by an initial increase in blood flow, enhances vascular permeability, influx of inflammatory cell from the peripheral blood into the connective tissue, and the clinical soft tissue alteration during the state of gingivitis, this alteration includes redness, edema, bleeding and tenderness ${ }^{(2)}$, while periodontitis is a destructive form of periodontal disease, it is an irreversible inflammatory state of the supporting structure ${ }^{(3)} \cdot \alpha$-L-Fucose is a methyl pentose sugar similar to L-galactose except for the loss of alcohol group on carbon number six $\left(\mathrm{C}_{6}\right)$, with a general formula $\mathrm{C}_{6} \mathrm{H}_{12} \mathrm{O}_{5}$ and a molecular weight of $164.16 \mathrm{~g} /$ $\mathrm{mol}^{(4)}$. Fucose is naturally found in D- and L-forms. The L-form is the only common form of the sugar, while the $\mathrm{D}$-form is a synthetic galactose analogue ${ }^{(5)}$,The L-form is found in mammalian tissues and fluids, while D- form is identified in plants.Purified L-Fucose is white powder and it melts at $153-155 \dot{\mathrm{c}}^{(6)}$, and L-fucose exist in two different forms $\alpha$-L-fucose $(29.5 \%)$ and $\beta$-L-fucose $(70.5 \%){ }^{(7)}$

Studies showed the importance of serum, saliva and 
gingival fluid fucose and its related parameters in the detection of oral disease, such as; gingivitis, periodontitis and oral cancers $(8,9,10,11,12)$. It was histologically showed, that fucose local injection into rabbit tongue muscle caused a reduction in the inflammatory process, 168 hours after injection, accompanied by regeneration in both oral mucosa and muscele layer ${ }^{(13)}$. Another study reported that sulcular injection of $\alpha$-L-Fucose into healthy gingival tissue had no local side effect on the injected tissue and could be used as a suitable method for administration in treatment of gingival disease induced by mechanical trauma (non-plaque induced gingival disease) ${ }^{(14)}$

\section{METHODS}

This study was conducted from 10 th June 2013 to 10 ${ }^{\text {th }}$ December 2014. in Hawler Medical University, College of Dentistry, Department of Basic Science, and Clinical Biochemistry Laboratory, Baghdad University, College of Dentistry, Department of oral Diagnosis and Histology Laboratory. The study was carried out on (60) male rabbits of the same species and nearly the same age (10-12 months), with a weight range of (1-1.5 kg). These rabbits were allowed to acclimate at least 7 days prior to the experiment in well arrayed room to ensure the same type of food to be taken by these rabbits and the same condition of temperature $\left(25-30^{\circ} \mathrm{c}\right)$. From the total number, 5 rabbits had been chosen randomly and were sacrificed immediately (the rabbits were free from gingival inflammation and not receive any local injection), while the rest 55 rabbits had gingival inflammation (gingivitis) and this was obtained by ; first the rabbits were weight , anesthetized with subcutaneous injection of xylazin (4 $\mathrm{mg} / \mathrm{kg}$ ) and ketamine $(40 \mathrm{mg} / \mathrm{kg})$ at the posterior part of the neck as a general anesthesia to facilitate handling of the animals cited by ${ }^{(15,16)}$, then a notch (concavity area) was made in the cervical area at the mid- labial aspect of lower right central incisor adjacent to the gingival margin with \# 8 round bur, that attached to the portable hand piece

The notch extended into the dentin and carried slightly adjacent to subgingival area (figure 1) modified of (17), after that the rabbits had been left for 10 days, during this period the notch area became site for subsequent plaque formation, and gingival inflammation (gingivitis) (figure 2), which had been characterized by presence of clinical signs of inflammation; as swelling, redness, loss of contour and bleeding of gingiva by probing. Finally the rabbits with gingivitis were divided randomly into three main groups:-

a. Gingivitis non injected group (G group), consisted of 5 rabbits with gingival inflammation only and were not received any sulcular injection, periodontal tissue samples were collected immediately after 10

The head was separated from the rest of body, then the mandible was separated from

the skull, muscles and the soft tissue covering the mandible were removed using a surgical days of placing notch area and induction of gingival inflammation.

b. Gingivitis saline injected group (GSI group), consisted of 25 rabbits. These 25 rabbits were divided randomly into 5 subgroups; GSI1, GSI2, GSI3, GSI4, and GSI5. Each subgroup consisted of 5 rabbits, these subgroups area of the bottom of gingival sulcus of the lower right central incisor with a single dose of normal saline of $50 \mu \mathrm{l} / \mathrm{kg}$ rabbit weight of normal saline solution $(0.9 \% \mathrm{NaCl})$, then periodontal tissue samples were taken at different time intervals of 1day(GSI1), 3day(GSI2), 7days (GSI3), 14 days (GSI4), and 21 days (GSI5) after normal saline injection. Then periodontal tissue samples were prepared for histopathological studies.

c.Gingivitis fucose injected group(GFI group), consisted of 25 rabbits and were divided randomly into 5 subgroups; GFI 1, GFI 2, GFI 3, GFI 4, and GFI 5 subgroups . Each subgroup consisted of 5 rabbits that received sulcular injection of a single dose of $50 \mu \mathrm{l} / \mathrm{kg}$ rabbit weight of $150 \mathrm{mM}$ of fucose dissolved in normal saline into the same area as in gingivitis saline injected subgroups, then these subgroups were sacrificed at the same time intervals of 1day (FGI1) , 3 days (FGI2), 7days (FGI3) ,14days (FGI4), and 21 days (FGI5) after fucose injection respectively. Periodontal tissue samples were sent for histopathological studies.

\section{Fucose solution preparation.}

$1.2312 \mathrm{~g}$ of $\alpha$ - L-fucose was dissolved in normal saline $(0.9 \% \mathrm{Na} \mathrm{Cl})$, and completed into $50 \mathrm{ml}$ by normal saline $(150 \mathrm{mM} \text { fucose })^{(14)}$.

$1.2312 \mathrm{~g}$ of of $\alpha$ - L-fucose was obtained from the following equation:

weight of fucose $(\mathrm{g})=$ mollarity $(\mathrm{mol} / \mathrm{L}) \times$ molecular weight $\times \operatorname{volume} 1(\mathrm{ml}) / 1000$

$=0.15(\mathrm{~mol} / \mathrm{L}) \times 164.16 \times 501000 /$

2-Sulcular injection technique and administration of L-fucose.

In this technique the needle was inserted from the gingival margin into thesulcular tissue at the bottom of the gingival sulcus 18 , In sulcular injection, the needle was inserted from the gingival margin approximately $5 \mathrm{~mm}$ (The needle was painted at the level of $5 \mathrm{~mm}$ distance from the tip and then stoper was placed over the painted area) into the sulcular tissue at the bottom of the gingival sulcus of the lower right central incisor, the solution was injected slowly and carefully throughout ten seconds ${ }^{(14)}$.

\section{2- Periodontal tissue sampling.} were received sulcular injection into the mid-labial 
blade, then the lower right anterior region of the lower right jaw was excised and cut off with saw and preserved in formalin $10 \%$, finally it was used for histopathological study $(16,19)$.

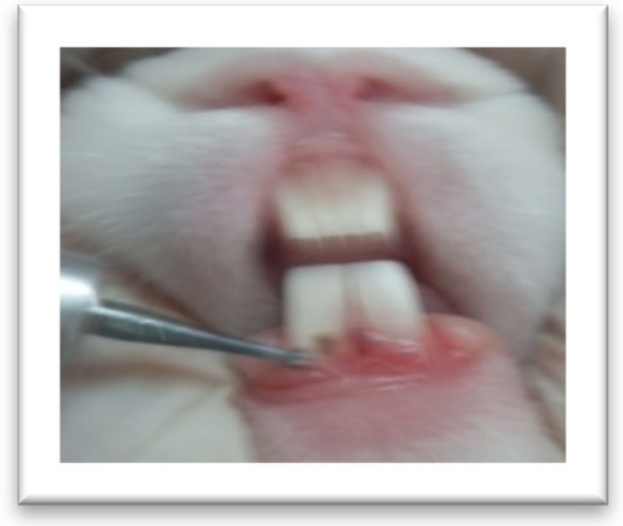

Figure1:Method of making notch

incisor

3-Histopathological examination.

The histological sections analyzed at different magnification of (X100, X200, X400, and X600) under a digital biological light microscope. In comparison with gingivitis non injected group, the changes in gingival tissue of gingivitis fucose and gingivitis saline injected subgroups were recorded.

\section{4-Histometric measurements.}

The thickness of oral epithelia was measured from the crest of marginal gingiva, for each section by the use of calibrated eye piece micrometer ${ }^{(19)}$

\section{5-Evaluation of inflammation.}

It was performed in accordance with the method proposed by a study ${ }^{(20)}$.

The severity of inflammatory reaction was obtained by calculating the number of inflammatory cells within magnification power of $\mathrm{x} 400$ for control group, saline and fucose gingivitis injected subgroups according to the following scores:

1 - Score 0 , none or few inflammatory cells, from 0 to less than 5 , no inflammatory reaction.

2 - Score 1 , the numbers of inflammatory cells are from 5 to less than 25, mild inflammatory reaction.

3 - Score 2, the numbers of inflammatory cells are from 25 to less than 125 cells, moderate inflammatory reaction.

4- Score 3, the numbers of inflammatory cells are more or equal to 125 cells, sever inflammatory reaction

\section{Statistical analysis}

All data were expressed using descriptive statistic as mean \pm standard deviation SD, and inferential statistics which include Paired $\mathrm{T}$-test, statistical analysis were carried out by using statistical software (SPSS version 22), the results were considered significant if $\mathrm{P}$ value $\leq 0.05$.

RESULTS

1-Histopathological results

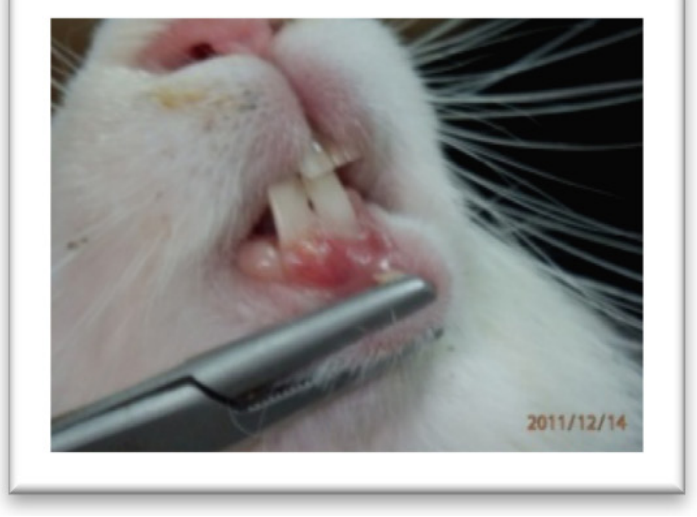

Figure 2:Ginigivitis in lower right central

Figure (1) shows the parakeratinized oral epithelial of normal rabbits without gingival inflammation with its normal oral epithelia thickness and presence of finger like projection of epithelia rete peges .The subepithelial connective tissue region showed well arranged bundles of collagen fibers, fibroblast cells, and few inflammatory cells infiltrated the area, and with well attachment of junctional epithelia into the root surface. Figure (2) shows the parakeratinized oral epithelial of rabbits with gingivitis non-injected group $(G)$, which consisted of stratified squamous epithelia with its typical basal, spinosum, granulosum and cornium layers, the thickness of the oral epithelium is slightly increase with presence of vacuoles in the prickle cells layers and the epithelial rete peges are flatten in most of the region but remain pointed in other region, the lamina propria showed moderate inflammatory cells infiltration especially in the lower and sulcular part , destructed collagen fibers, and destructed blood vessels (sever hemorrhage). Then after 1day of fucose solution injection into rabbits with gingivitis figure(3) shows slight reduction in the oral epithelial thickness with remaining of vacuoles in some area of prickle cell layers, slightly appearance of epithelia rete pege in some areas of oral epithelia, deepening of gingival sulcus, and new attachment of junctional epithelia into the root tooth surface. The lamina propria below oral and sulcular epithelia still showed moderate inflammatory reaction, well arranged collagen fibers , and beginning of new capillaries formation. The fibrous tissue appear especially in the sulcular part of lamina propria (more fibroblast cells with its more well formed collagen fibers formation) , while after 3 days of fucose injection figure (4) shows that the parakeratinized oral epithelia revealed more reduction in oral epithelia thickness, 
disappearance of the vacuole in the epithelial layers, presence of slightly widely epithelia rete peges, and great reduction in the depth of gingival sulcus. The lamina propria below oral and sulcular epithelia showed reduction in the inflammatory reaction (mild inflammatory reaction),more well arranged collagen fibers formation, more fibroblast cells, and more new blood vessels formation. Then after 7 days of fucose injection, the oral epithelia still parakeratinized and showed normal thickness with finger like projection of epithelia rete peges and the lamina propria below oral epithelia showed well fibrous tissue formation with no inflammatory reaction ( few inflammatory cells infiltration ) and in the sulcular part , more well arranged fibrous tissue can be seen ( more fibroblast cells and more well collagen fibers formation) with no inflammatory cells infiltration figure (5), and after 14 and 21 days of fucose injection, the lamina propria below oral and sulcular epithelia appear normal ( no inflammatory reaction with well formed fibrous tissue regeneration) as shown in figure (6). While 1 day after sulcular injection of saline; the parakeratinized oral epithelia showed an increase in oral epithelia thickness with tearing of base of gingival sulcus, and moderate inflammatory reaction in the lamina propria. This increase in oral epithelia thickness and moderate inflammatory reaction still present continued after $3,7,14$,and 21 days from saline injection as shown in figure 7,8 and 9 .

\section{2- Histometric measurments results:-} a- Thickness of oral epithelia.

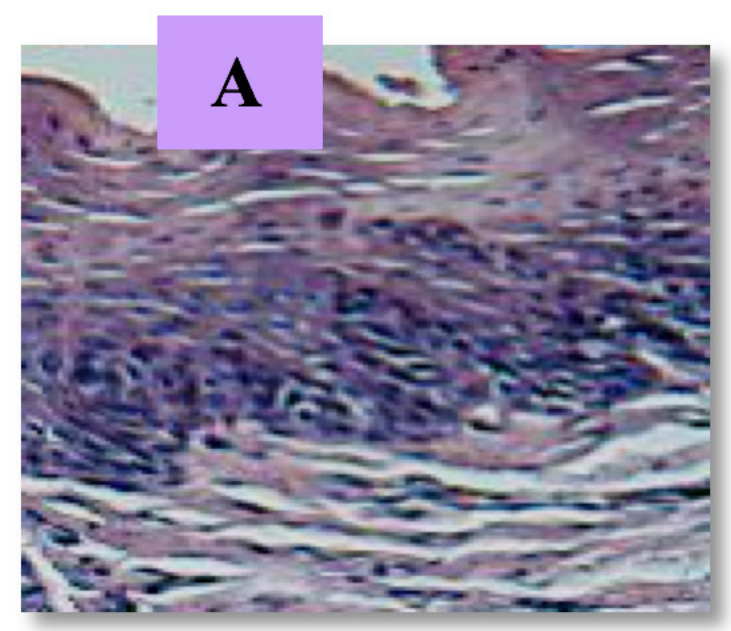

Table (1), shows that the mean value thickness of oral epithelia in normal rabbits without gingival inflammation was $(120 \pm 2.98)$ and was increased with gingival inflammation in gingivitis non- injected group into (199.84.02 \pm ), then after fucose solution injection into rabbits with gingivitis, the mean value thickness of oral epithelia decreased significantly after1 day of fucose injection $(191 \pm 2.64)$, and continued to decrease with significant differences with gingivitis non- injected group after different time intervals of 3,7,14,and 21 after fucose injection ( 170 \pm 2.73$),(122.8 \pm 2.13),(121.2 \pm 0.83)$, and $(121.4 \pm 0.54)$ respectively .

Table (2) shows the mean value thickness of oral epithelia in gingivitis non- injected group was (199.84.02 ), and after saline injection into rabbits with gingivitis, the results showed that the mean value thickness of oral epithelia was still increased with no significant difference with the gingivitis non injected group after different time intervals of $1,3,7,14$, and 21 days after saline injection (198.6 \pm 4.61), $(198.6 \pm 2.38),(197.2 \pm 4.21),(197.6 \pm$ $1.30)$, and $(196.2 \pm 1.16)$ respectively.

\section{b- Evaluation of inflammatory reaction:-}

Table (3), shows that the inflammatory reaction was moderate ( score 2) in rabbits with gingivitis-non injected group, and after 1 day of fucose solution injection the inflammatory reaction remain moderate, then reduced to mild inflammatory reaction (score 1) after 3 days of injection, and finally no inflammatory reaction (score 0 ) was observed after 7, 14, and 21 days of fucose injection. While after sulcular injection of saline into rabbits with gingivitis ,the inflammatory reaction remain moderate (score 2) after 1,3,7,14,and 21 days of saline injection .

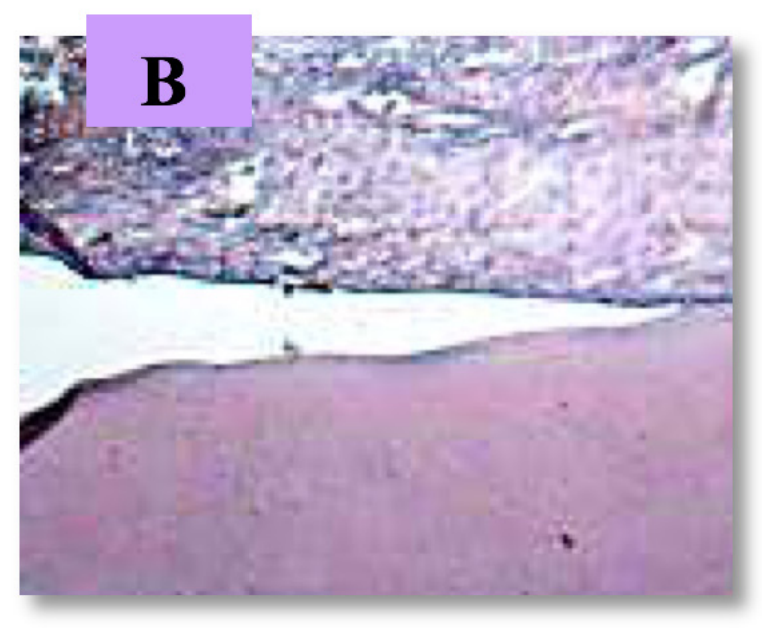

Figure1: Normal rabbit with healthy gingiva shows A- parakeratenized oral epithelia and underlying connective tissue with well arranged collagen fibers and no inflammatory reaction B- gingival sulcus with attachment of junctional epithelia into the root tooth surface(X200A,X100B). 

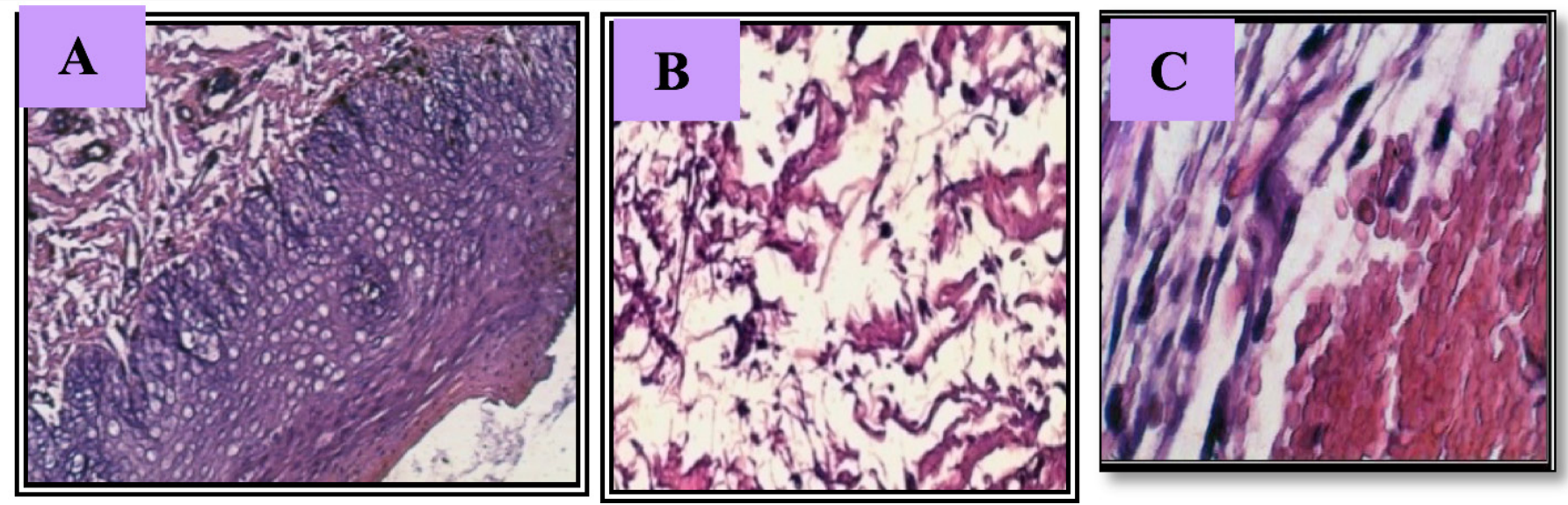

Figure2:Rabbit with gingivitis shows A-parakeratenized oral epithelia and connective tissue B-moderate inflammatory reaction in lower part of connective tissue $\mathrm{C}$ - moderate inflammatory reaction with destructed collagen fibers and blood vessels in sulcular area $(\mathrm{X} 200 \mathrm{~A}, \mathrm{X200B}, \mathrm{X600C)}$.
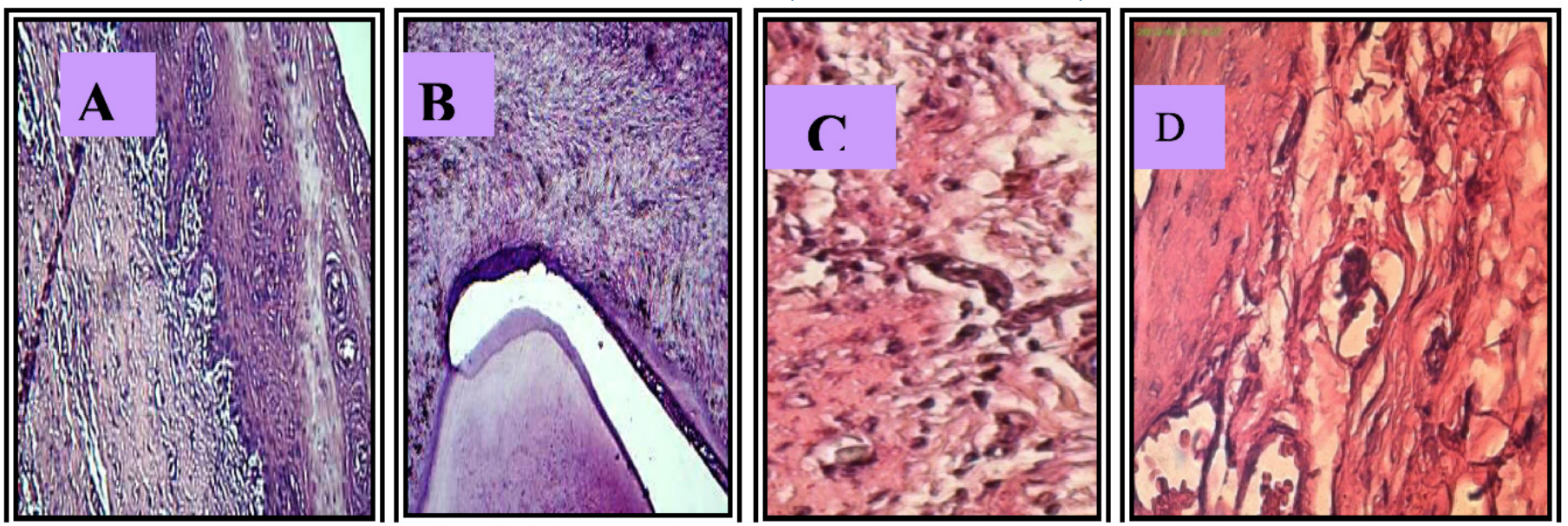

Figure3: Rabbits with gingivitis, 1 day after sulcular injection of fucose shows A-oral epithelia and connective tissue B-deepening of sulcus and new attachment of junctional epthelia to the root surface $C$-moderate inflammatory reaction in connective tissue Dsulcular area with well arranged collagen fibers and new blood vessels formation (X100A,X100B,X200 C, X600 D)
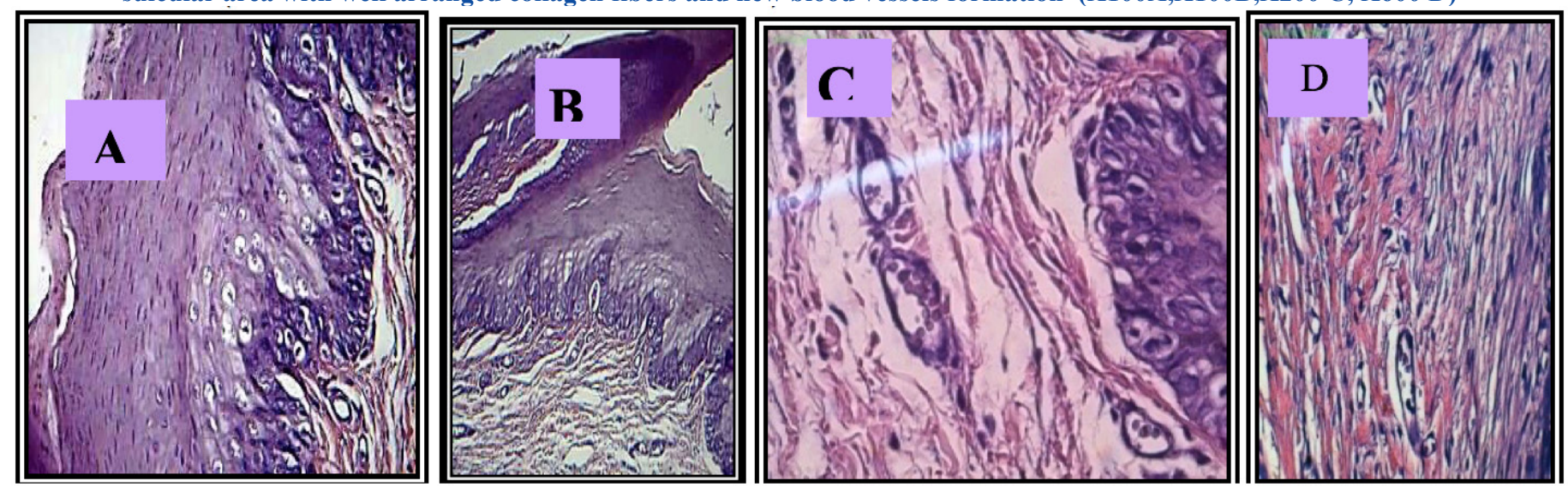

Figure 4: Rabbits with gingivitis , 3 days after sulcular injection of fucose show A- par keratinized oral epithelia and epithelia rete pege with prominent basal cell layer $B$ - reduction in depth of gingival sulcus $C$ - connective tissue with mild inflammatory reaction, well arranged collagen fibers and new blood vessels formation $D$ - sulcular area with well arrangement of fibrous tissue $(\mathrm{X} 200 \mathrm{~A}, \mathrm{X100B}, 600 \mathrm{C}, \mathrm{X} 400 \mathrm{D})$. 

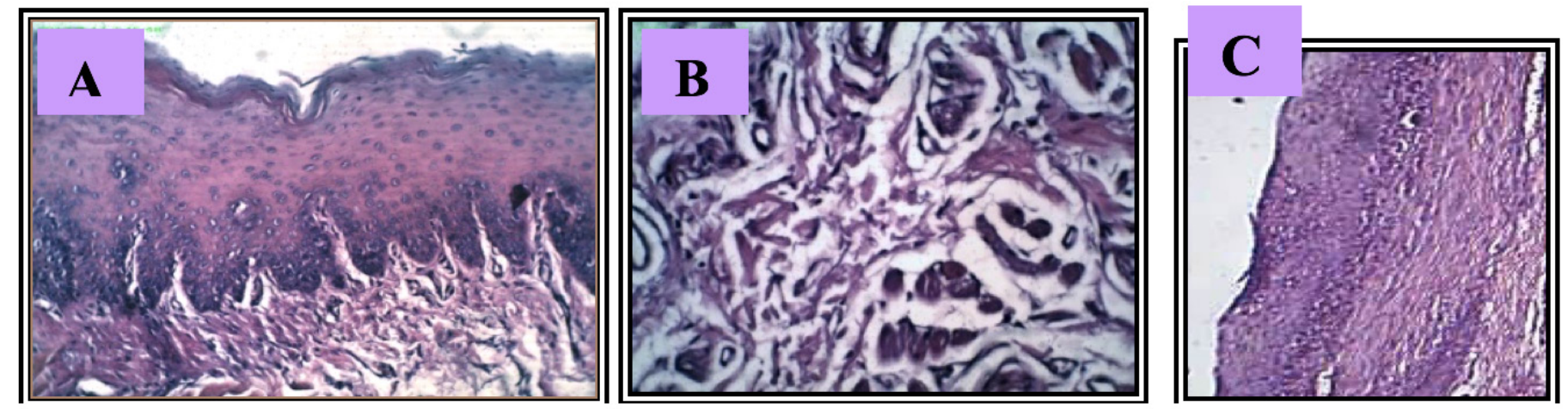

Figure 5: Rabbits after 7 day of sulcular injection of fucose show A-oral epithelia and finger like projection of epithelia retepeges $B$ - connective tissue with no inflammatory reaction and well organized fibrous tissue $C$ - sulcular epithelia and underlying well organized fibrous tissue(X200A,X400B,X200 C).
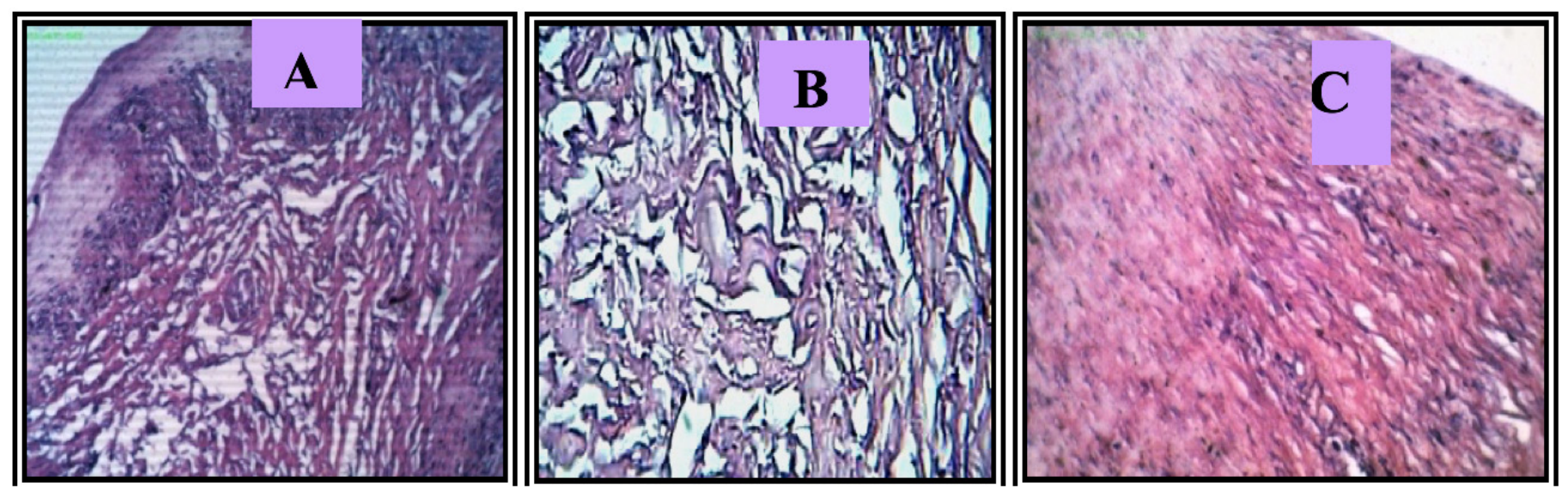

Figure 6: Rabbits after 14 day of sulcular injection of fucose show A- oral epithelia and underlying lamina propria B- lamina propria with no inflammatory reaction and more well organized fibrous tissue C-sulcular area with its well organized collagen fibers and fibroblast cells(X200A,X400B,X400 C).

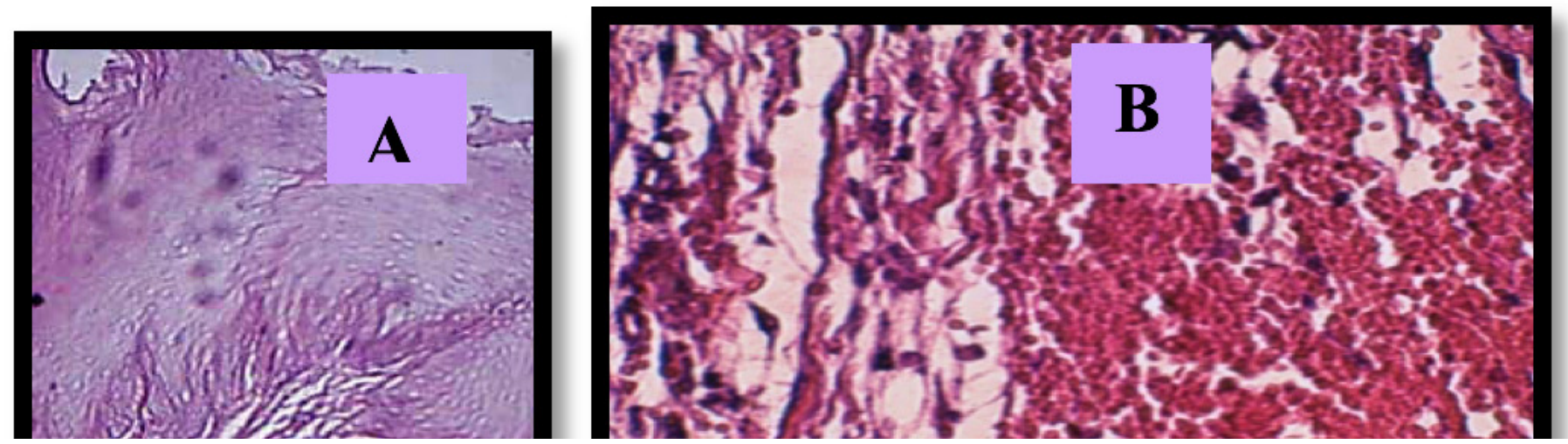

Figure 7: Rabbits with gingivitis ,1 day after sulcular injection of saline shows A-increase thickness of oral epithelia B- tearing of base of gingival sulcus C-lamina propria with moderate inflammatory cells infiltration, edema, and sever hemorrhage( destructed blood vessels) $\mathrm{H} \& \mathrm{E}(\mathrm{X} 200 \mathrm{~A}, \mathrm{X100B}, \mathrm{X} 400 \mathrm{C})$. 

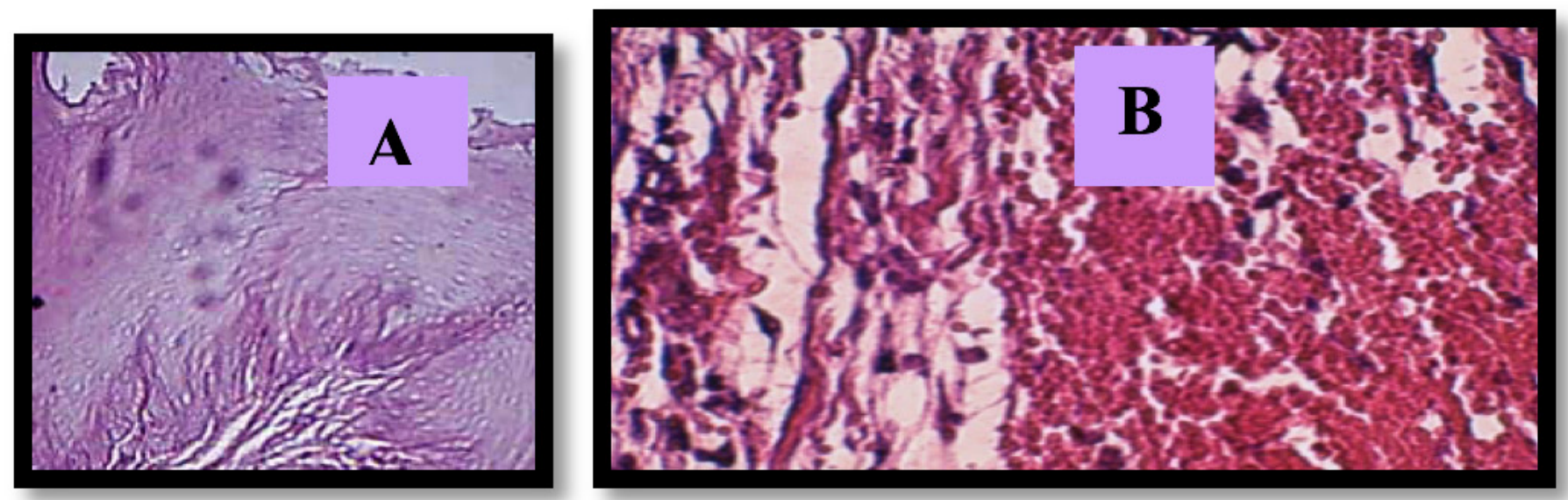

Figure 8: Rabbits with gingivitis ,3 days after sulcular injection of saline shows A-increase thickness of oral epithelia B- lamina propria with moderate inflammatory reaction, edema and destructed blood vessels ( X100A, X400B) .
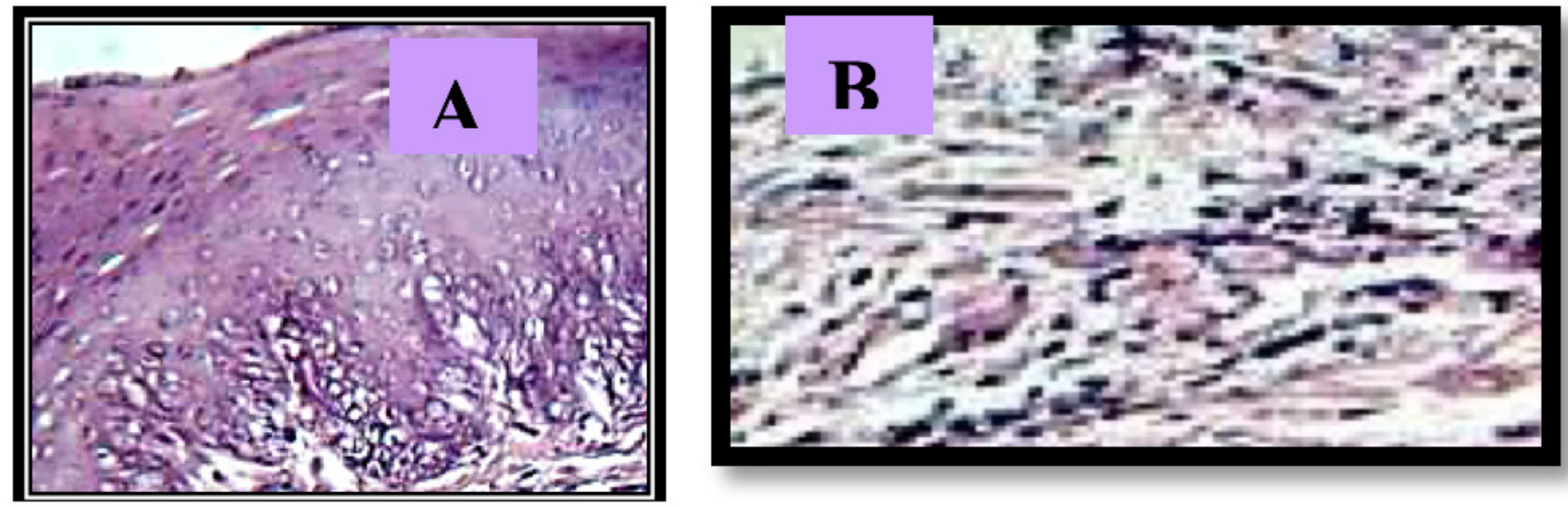

Figure 9: Rabbits with gingivitis ,21 days after sulcular injection of saline shows A-increase thickness of oral epithelia $\mathrm{B}-$ lamina propria with moderate inflammatory reaction(X200 A, X200 B).

Table (1):-The mean \pm standard deviation (SD) of oral epithelia thickness in gingivitis non-injected group (G) and fucose injected subgroups after different time intervals of sulcular injection with $50 \mu \mathrm{l} / \mathrm{kg} \mathrm{of} 150 \mathrm{mM}$ fucose solution ,P $\leq 0.05=$ Significant .

\begin{tabular}{|c|c|c|c|c|}
\hline Rabbits groups & Time intervals (Days) & Mean \pm SD & P-value & Sig. \\
\hline Normal rabbits & - & $120 \pm 2.98$ & & \\
\hline G & gingivitis non-injected group & $199.8 \pm 4.02$ & & \\
\hline GF1 & 1 day & $191 \pm 2.64$ & .037 & S \\
\hline GF2 & 3 days & $170 \pm 2.73$ & .000 & S \\
\hline GF3 & 7 days & $122.8 \pm 2.13$ & .000 & S \\
\hline GF4 & 14 days & $121.2 \pm 0.83$ & .000 & S \\
\hline GF5 & 21 days & $121.4 \pm 0.54$ & .000 & S \\
\hline
\end{tabular}

Table (2):-The mean \pm standard deviation (SD) of oral epithelia thickness in gingivitis non-injected group (G) and saline injected subgroups after different time intervals of sulcular injection with $50 \mu \mathrm{l} / \mathrm{kg}$ of saline solution, $\mathrm{P} \leq 0.05=\mathrm{Signifi}-$

cant.

\begin{tabular}{|c|c|c|c|c|}
\hline Rabbits groups & Time intervals & (Days) & Pean \pm SD & Sig. \\
\hline Normal rabbits & - & $120 \pm 2.98$ & & \\
\hline G & gingivitis non-injected group & & $199.8 \pm 4.02$ & NS \\
\hline GS1 & 1day & $198.6 \pm 4.61$ & .587 & NS \\
\hline GS2 & 3 days & $198.6 \pm 2.38$ & .395 & NS \\
\hline GS3 & 7days & $197.2 \pm 4.21$ & .360 & NS \\
\hline GS4 & 14 days & $197.6 \pm 1.30$ & .100 & NS \\
\hline GS5 & 21 days & $196.2 \pm 1.16$ & .321 & \\
\hline
\end{tabular}


Table (3): The score and number of inflammatory cells (N) in normal rabbit, gingivitis non injected group, gingivitis fucose injected group, and saline injected group after different time intervals of sulcular injection.

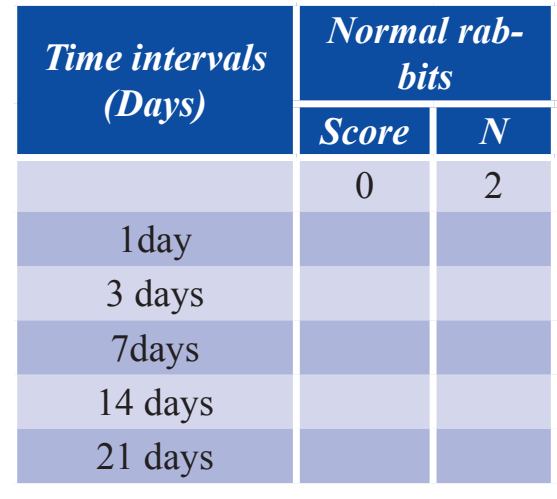

Score (0) no inflammation

\section{DISCUSSION}

To the best of our Knowledge, it's the first study to evaluate the effect of sulcular injection of fucose on the inflamed gingival tissue in case of gingivitis. The histopathological study revealed that after 1 day of fucose solution injection resulted in rapid reepithelization and new attachment of junctional epithelia into the root tooth surface that was tea red and injured normally by sulcular injection method with fibrous tissue and new capillaries formation in lamina propria , then reduction of inflammatory reaction was seen after 3 days of fucose injection, with well organized collagen fibers, and more new blood vessels formation and after different time intervals of 7 days, 14 , and 21 days the connective tissue was heal from any inflammatory reaction especially in the sulcular part with fibrous tissue and new blood vessels formation, while after saline injection, the moderate inflammatory reaction remain even after 21 days of saline injection. These results were nearly in the same line with a study conducted to evaluate the histopathological effect of local injection of fucose in normal saline into healthy gingival tissue and reported that fucose injection resulted in rapid reepitheliazation and new attachment of junctional epithelia into the tooth surface ( 3 days after injection) and that that the inflammatory reaction didn't continue for long time and the healing processes appeared at the examined site, 3days after injection ${ }^{(14)}$. The researcher also concluded that fucose can be used as anti-inflammatory agent in the treatment of gingival disease induced by mechanical trauma biochemically and immunologically, throughout its stimulatory effect in enhancement of endogenous secretion of vitamin $\mathrm{C}$ for long duration of time after injection (reached a peak in 3days after injection) which assist in healing of damaged gingival connective tissue and throughout its inhibitory effect in the decrease production of both proinflammatory cytokines IL-1 beta and TNF-alpha after fucose injection ${ }^{(14)}$.

Another study coincide with our result, revealed that after local injection of fucose in normal saline into rabbit tongue muscle ,the inflammatory reaction didn't continue for long time and the healing processes appeared at the examined site, $168 \mathrm{hrs}$ after injection. She concluded

\begin{tabular}{|c|c|c|c|}
\hline $\begin{array}{c}\text { Gingivitis fucose injected } \\
\text { subgroups }\end{array}$ & \multicolumn{2}{|c|}{$\begin{array}{c}\text { Gingivitis saline injected } \\
\text { subgroups }\end{array}$} \\
\hline Score & $\boldsymbol{N}$ & Score & $\boldsymbol{N}$ \\
\hline & & & \\
\hline 2 & 77 & 2 & 79 \\
\hline 1 & 20 & 2 & 76 \\
\hline 0 & 3 & 2 & 79 \\
\hline 0 & 0 & 2 & 76 \\
\hline 0 & 0 & 2 & 75 \\
\hline
\end{tabular}

Score (2) moderate inflammation that after fucose injection; many signs of reduction in the inflammatory process in the lamina propria (LP) were seen accompanied by many signs of regeneration in lamina propria which was represented by the present of many active fibroblast and newly formed collagen fibers ${ }^{(13)}$.

Another study conducted to reveal the effect of local application of $0.5 \mathrm{mg} / \mathrm{ml} \mathrm{L}$ - fucose on corneal lesion in rabbit, and reported that L-fucose reduced significantly matrix metalloproteinase -9 (MMP-9) upregulation and activation ( $24 \mathrm{hrs}$ after burn), and accelerated the recovery of the epithelial layer of the cornea. The researchers reported that there was relatively rapid regrowth of epithelium and the speed of this reepitheliaization was stimulated by the local application of fucose and they found at 48 hours after burn there was a difference between epithelia thickness of fucose-treated corneal lesion and epithelia thickness of control corneas (epithelial thickness was increased in fucose-treated corneas than the control corneas) ${ }^{(21)}$. In the same context the researchers studied the effect of fucose on normal corneas, which was added to rabbit as well as human cornea explant cultures, and the production and release of MMP-9 was determined by zymography. They found that fucose at a concentration of $0.5 \mathrm{mg} / \mathrm{ml}$ produced a 70\% decrease of MMP-9 activity released in the medium by corneal explant cultures. From these results justify the use of fucose for the local treatment of corneal wounds ${ }^{21}$. These previous results were conincide with our result which showed that after 1 day of fucose injection , resulted in enhancement of regeneration of junctional epithelia cells and accelerated reepithelialization and new attachment of junctional epithelia into the root surface after tearing of the base of sulcus immediately by sulcular injection method ${ }^{(14)}$. This rapid reepithelialization and new epithelial attachment prevent the entrance of bacterial plaque and their product into the gingival connective tissue so can assist in healing of gingival disease induced by plaque (gingivitis) .

Researchers, measured the efficiency of fucose and fucose- rich polysaccharides to down regulate the elastase type endopeptidase activity by using skin explant cultures and fibroblast explant culture. In skin explant cultures, they 
found that fucose and fucose rich preparation produced an inhibition of the activiation of the proform to active form of MMP-9 due to mono, and polysaccharides acting on elastin-laminin receptor / or on the fucose-mannose receptor which are efficient inhibitors of such enzymes by down regulating elastase - type endopeptidase activity, both at the level of the biosynthesis and at the level of the activiation of the pro-enzymes. They concluded that fucose and fucose-rich preparation were show to be efficient modulatory of MMP-2 and MMP-9 activity with potential therapeutic application for tissue loss in aging ${ }^{(22)}$.

Similarly, in dermal fibroblast explant culture , the percutaneous application of an L-fucose-containing preparation penetrated in the dermis and produced an increase of skin thickness and a densification of collagen bundles due to favorable activities of L-fucose on the down regulation of matrix-degrading enzymes (MMP-2 and MMP-9) and increased fibroblast cells proliferation $(23,24)$

result which show that fucose injection stimulate cells proliferation,especially fibroblasts and collagen fibers production. Another study, revealed that the novel pharmacological properties of L-fucose and fucose-rich oligo- and polysaccharides (FROP-s) might be related to their accelerating effect of wound healing ${ }^{(25)}$. In another study, the researchers tested the cyto-protective effect of L-fucose and FROP-s and showed that relatively low concentrations of L-fucose could efficiently penetrate skin , protect fibroblasts from the ascorbate-induced cell-death by stimulate fibroblast cells proliferation to slow down skin aging ${ }^{(26)}$.These results were similar to our results that show fucose sulcular injection stimulate fibroblast cells formation and collagen fibers production that induce healing of the gingival connective tissue.

Regarding to saline injection, the results showed that saline had no any effect on the healing of inflamed gingival tissue by plaque and the inflammatory reaction continued even after 21 days from saline injection, this result was nearly on the same line with another results which showed that sulcular injection of saline had no any effect on the healing of inflamed gingival tissue by mechanical trauma even after 21 days after injection ${ }^{(14)}$.

So in the condition of gingivitis the study results indicated that fucose sulcular injection, can be used as therapeutic anti-inflammatory agent in the treatment of gingivitis .

\section{CONCLUSION}

Sulcular injection of fucose accelerated reepithelization and new attachment of junctional epithelia into the root tooth surface in short duration of time (1day after fucose injection) with new blood vessels and fibroblast cells formation and fibroblast proliferation to produce collagen fibers to form fibrous connective tissue (fibrous tissue regeneration) and also fucose injection resulted in reduction of the inflammatory reaction gradually ( 3 days after injection) which suggest the use of fucose as antiinflammatory agent in the treatment of gingivitis (gingival inflammation induced by bacterial plaque), many studies need to support this conclusion, so we can be able to translate its anti-inflammatory effect from an experimental animals into human being.

\section{REFERENCES}

1. Scully D and Langley-Evans C. Periodontal disease is associated with lower antioxidant capacity in whole saliva and evidence of increased protein oxidation. Clinical Science 2002;105:167-172.

2. Pourhashemi S, Motlagh M and Khaniki G .Prevalence and Severity of Gingivitis among 6-12 years old Elementry School Children in Tehran. J.Med.Sci.7(5):830-834.

3. Kinny J, Ramsier C and Giannobile W . Oral fluid-based biomarkers of Alveolar bone loss in Periodontitis..Ann. N.K. Acad .Sci. 2007; 1098 : 230 -251.

4. Moriwaki $k$ and Miyoshi E. Fucosylation and gasterointestinal cancer. Word J Heptaol 2010; 2 (4) :151-61.

5. AlanW. Fucose.e-Newsletter.American International Association 2006.

6. Becker DJ and Lowe JB .Fucose :biosynthesis and biological function in mammals. Glycobio 2003; 13(7): 41-53.

7. 7.Park D, Ryu KS, Choi JK and ParkC ..Characterization and role of fucose mutarotase in mammalian cells. Glycobiology 2007;;17(9):955-962.

8. Shetty PK, Pattabiraman TN. Salivary glycoprotein as indicators of oral diseases. Indi J Clini Bioch 2004;19(1) : 97-101.

9. Shah M, Telang S, Ravel G, Shah P and Patel PS.Serum fucosylation changes in oral and precancerous conditions. Cancer 2008 ;113 (2):336-346

10. Abbas LB and Ahmed SA . Serum total $\alpha$-L-fucose and related parameters in breast cancer as tumor marker 2011; 9 (1).

11. Mahmood Y CH. ASSESSMENT OF SOME SALIVARY BIOCHEMICAL COMPOSITION IN CIGARETTE SMOKER WITH CHRONIC PERIODONTITIS. 2011 Master thesis, College of Dentistry, Hawler Medical University, Iraq.

12. Wsoo MA. Biochemical Studies on Salivary $\alpha$-L-Fucose and its related parameters in periodontitis 2012. Master thesis.College of Science . Koya University .Iraq

13. Omer RM. Effect of $\alpha$ - L-fucose on Rabbit tongue muscle 2010. Phd thesis, College of Dentistry, Hawler Medical University,Iraq.

14. Mohammad $\mathrm{CH}$ A.The effect of intracrevicular gingival injection of $\alpha$ - L-fucose. Biochemical,Immunological and Histopathological study on rabbits 2013. Phd thesis

College of Dentistry, Hawler Medical University,Iraq.

15. Hedenqqvist P. Anasthesia and analgesia for surgery in rabbits and rats: A comparison of the effects of different compounds 2008.Ph.D thesis,stockholm,sweden.

16. Hussien SS. Hitological effects of ciprofloxacin and ceftriaxone on the healing process of the alveolar bone 2011.Master thesis .College of Dentistry, Hawler Medical University

17. Froum SJ, Tarnow D, Caiazo A and Hochman MN (2000). 
Histologic Response to Intraligament Injections Using a Computerized Local Anasthetic Delivery System.A Pilot Study in Mini- Swine. J Periodontal 2000. 1.7(9). NewYork University. NewYork.

18. Peterson JE, Matsson L and Nation W. Cementum and epithelial attachment response to the sulcular and periodontal ligament injection techniques. Pediatric Dentistry. The American Academy of Periodontology 1983; 5(4).

19. Taka S Sh.The local effects of S2-complex on periodontium 2001. Master thesis, College of Dentistry, Baghdad University.

20. Yalitrik M, Ozbas H, Bilgic B, Issever $\mathrm{H}$ et al. . Reaction of connective tissue to mineral trioxide aggregate and amalgam J Endod 2004; 30(2):95-9.

21. Isnard N, Bourles-Dagonet F, Robert L and Renard G - Studies on corneal wound healing. Effect of fucose on Iodine vapor-burn rabbit corneas.Opthalmologica. 2005;219(6): 324-33.

22. Isnard N, Péterszegi G, Robert AM and Robert L .Regulation of elastase -type endopeptidase activity, MM-2 and MM-9 expression and activiation in human dermal fibroblast by fucose and fucose-rich polysaccharide 2002. 56(5):258-
64.

23. Fodil-Bourahla I, Bizbiz L, Schoevaert D , Robert AM and Robert L .Effect of L-fucose and fucose-rich oligoand polysaccharides (FROP-s) on skin aging: penetration , skin tissue production .and .fibrillogenesis 2003..57(56):209-15..[Biomed.Pharmaco-therapy]-Pubmed.

24. Péterszegi G, Isnared N, Robert AM and Robert L ."Studies on skin aging. Preparation and properties of fucoserich oligo and polysaccharides. Effect on fibroblast proliferation and survival 2003a.57(5-6):187-194. [Biomed pharmacotherapy]- Pubmed.

25. Péterszegi G, Fodil-Bourahla I, Robert AM and Robert L .Pharmacological properties of fucose. Applications in agerelated modifications of connective tissues. 2003b;57(5-6): 240-245.

26. Péterszegi G, Robert AM and Robert L. Protection by L-fucose and fucose-rich polysaccharides against ROSproduced cell death in presence of ascorbate.. 2003c ;57(34):130-133..[Biomed pharmacotherapy]. 